\title{
Competitive Innovation Strategies and Their Effect on Enhancing Organizational Effectiveness: Talent Management as a Moderator
}

\author{
Azzam A. Abou-Moghli ${ }^{1}$ \\ ${ }^{1}$ Department of Business Administration, Faculty of Business, Applied Science Private University, Jordan \\ Correspondence: Azzam A. Abou-Moghli, Department of Business Administration, Faculty of Business, Applied \\ Science Private University, Jordan. E-mail: a_aboumoghli@yahoo.com
}

Received: February 3, 2019

Accepted: February 22, 2019

Online Published: March 8, 2019

doi:10.5539/ijbm.v14n4p24

URL: https://doi.org/10.5539/ijbm.v14n4p24

\begin{abstract}
Innovation strategies significantly contribute to the enhancement of organizational competitive advantage. Talent management is considered as a stimulator improving the organization performance. The purpose of the study is to evaluate the effect of competitive innovative strategy on organizational effectiveness in relation to talent management. The quantitative design is applied using a questionnaire-based survey. A total of 279 participants were recruited for collecting data which was analyzed using SPSS. Descriptive and inferential statistics were computed along with chi-square. The results have shown a significant and positive effect of process innovation, retention, and attraction on organizational effectiveness. In addition, the study has found a positive and significant moderating role of retention, engagement, and attraction on process innovation and organizational effectiveness. However, the study fails to find any significant effect of engagement on organizational performance, competitive advantage, and total positioning. In order to improve organization competitive edge, the study recommends investing in the talent management and development for enriching its intellectual capital, which serves as a great asset for competitive advantage.
\end{abstract}

Keywords: competitive innovation strategies, organizational effectiveness, talent management, Jordan

\section{Introduction}

Given the current business practices, it is integral for organizations to sustain an innovative edge to ensure their survival in the competitive business environment (Distanont, \& Khongmalai, 2018). Enhancement of organizations' performance and competition is associated with their capability to acquire their determined objectives by assimilating their various components such as innovative strategies, good control, and talent administration, while also modifying their strategies as per the prevailing market conditions (Hotho, Lyles, \& Easterby-Smith, 2015).

Instigation of innovative strategies have been supported by various researches (Adnan, Abdullah, \& Ahmad, 2016; Martín-de Castro et al., 2013). Such as, it has been indicated that innovation stimulates the performance of the organization in both monetary and non- monetary terms. Kibisu and Awino (2017) adds the organization which lacks innovative strategies fail in the competitive environment and requires organizations to form a linkage between innovation and organizations' strategies. The innovative strategies inducing in the latest development and change over time also create value for stakeholders and helps in organizations' performance enhancement. This also leads to the formation of sustainable growth makes the organization competitive in external and internal markets (Virameteekul, 2011).

The research by Martín-de Castro et al. (2013) asserts towards the adaptations of the innovative technology for the creation and sustainment of the organization's competitive gain. In order to position oneself dominant, Zemplinerová (2010) have suggested investment in the research, development, and innovation of the organizations' diverse components. The significance of the innovative competitive strategies have also been highlighted by the survey results of Autant-Bernard et al. (2013). The survey also highlighted that in order to optimize the gain from the innovative strategies, novelty and knowledge flow must be sustained in the organization.

However, the implementation of the innovative strategies come with their own set of risk. Such as adversative diversion of the determined outcomes followed by a financial loss (Vaughan, 2014). It is highlighted that 
competitive innovation strategy instills the risk management stressing on the organization towards its control and financing. Supplementing this, Georges (2013) reports that risk management also promotes restructuring and reduction of risk through value maximization. This necessitates the following of a flexible thought and application process in-line with the altering circumstances. The innovation must flow among the various agents of the organization for their sharing of a common goal as well as effective execution (Perry-Smith \& Mannucci, 2017).

Camison and Villar-Lopez (2014) assert that innovative business practices help in enhancing the technologically oriented innovation as well as technology in other systems improving organization performance. Whereas Lu et al. (2010) establish that innovation improves the organizations' adaptation capability escalating its performance. Several researches have demonstrated that the prospects of business survival can be associated with a competitive advantage in a particular business environment (Tseng, Tan, \& Siriban-Manalang, 2013). The intensity of the competition is also related to the organization actions, and its response to the generation of revenue (Adnan, Abdullah, \& Ahmad, 2016). Moreover, it also integrates the promotion, resource development as well as the satisfaction of its stakeholders (Asomaning \& Abdulai, 2015).

Given the resource of the companies, the studies on talent management have increased in relation to the organization performance (Anwar et al., 2014; Fakhr El Din, 2013; Lyari, 2013). The concept of talent management dates back to 1980 s when the organizations were filtering out the best resources for exerting control and planning on their development which changes in 1990 (Anwar et al., 2014). In it, employees were given the control to plan their development accordingly, while following in 2000, the organizations presented an opportunity for their development. The significance of the talent management is also reported by Diab (2014) survey, which highlighted that $53 \%$ of CEOs were concern that insufficient talent within their organizations could adversely affect their financial performance.

A study by Anwar et al. (2014) suggest the formation of strategic practices in talent management for retaining and engaging employees accelerating the organization performance. Talent management also amplifies the organization product and process innovation in the organization making it smoother (Sintset Kenfac, Nekoumanesh, \& Yang, 2013). The talent development helps the organization in devising an innovative strategy which aligns the workforce skill with the organization objective, adding to its competitive advantage. Vaiman et al. (2012) highlight that the integration of talent management improves the retention and engagement of the employees, while also attracting the talented profiles in the market. The improved performance of the organization in relation to talent management has been endorsed by several studies (Anwar et al., 2014; Fapohunda, 2014).

The present literature provides that talent management has been studied by authors at a micro level (Björkman et al., 2013; Gelens et al., 2013; Gelens et al., 2014; Al-Qeed, 2016), which requires further exploration for its macro effect. For this, the study uses talent management for exploration of its effect as a moderator in organization innovative strategy focused on advancing its competitive advantage. Considering the economy of Jordan, the efforts are being made for leveraging the growth of the organizations in the economic market. Such as Diab (2014) showed that the Jordanian private hospitals are integrating the competitive components such as cost, flexibility, quality, and delivery for accomplishing achieve competitive advantage. Though, these remain limited among the web development industries. This is evident from the reporting of World Economic Forum Global Information Technology Report (2009-2010), which list Jordan on the poorest innovation indicators (Mohammed, 2011). Since the concept of talent management is accelerating, the study intends to evaluate its effect in terms of competitive innovative strategy in the Jordan economy. It is assumed that its results will contribute to the existing research on organizational effectiveness with regard to the three variables such as talent management, competitive advantage, and innovation strategies. Moreover, the study will provide guidance to the managers for utilizing the process of talent management as a part of its competitive innovation strategy. The objectives of the study are as follows (1) To explore the strategic significance of talent management in competitive advantage; (2) To evaluate the role of talent management in the enhancement of organizational effectiveness; and (3) To examine the relationship among innovative strategy, talent management, and competitive advantage.

\section{Conceptual Framework and Hypothesis Development}

The importance of innovational strategies in influencing the performance of an organization has been endorsed by many scholars in numerous studies, the investigations on this relationship has been performed in different economic sectors around the globe and relate strategies of innovation on successful performance of industries. For instance, García-Sánchez et al. (2018) claimed that product and process innovation is mandatory for 
companies to overcome market competitors specifically in present dynamic environments, where internal variables of an organization are encouraged to create competitive advantages. Internal variables include an organization resources, assets and adaptable designs, training of employees, management proficiencies and its coordination, and flexible policies of human resources. Tuan et al. (2016) suggest that to survive and grow in the competitive environment, organizations must dive deep in the ocean of innovations including product, process and marketing factors. Beyene et al. (2016) considering perspective on Ethiopian manufacturing organizations denotes two main ideologies i.e. effectiveness and efficiency of the organization is brought by innovational strategies for long-term survival. On the study of role of enhancing innovational strategies in telecommunication organizations, Hajir et al. (2015) explored that when organizations have efficient substructures, innovation upsurges and the organization preserves its competitive advantage in the industry.

Payambarpour and Hooi (2015) have noticed organizational effectiveness in a broader way; the study specifies that performance of global organizations is effected by management policies and human resource development in order to evaluate the relationship between employee management and organizational performance. In a different study conducted by Nijveld (2014) put forwards a consensus about talent management and its benefits on organizational effectiveness. He states that organizations need large resources to target trainings of employee and to develop managers on greater extent. There is a major effect of employee management in the financial outcomes of an organization Rastgoo (2016) indicates attraction and management of talent as two main factors of the dimensions of talent management. The study furthers claims that management should hunt for talented employees in an organization and reward them with opportunities, which will boost growth and prosperity of an organization. Based on the aforementioned discussion, following hypotheses have been presented;

H1a: Innovation strategies positively and significantly effects organizational performance.

H2a: Innovation strategies positively and significantly effects competitive advantage.

H3a: Innovation strategies positively and significantly effects talent positioning.

H4a: Retention positively and significantly moderates the relationship between innovation strategies and organizational effectiveness.

H5a: Engagement positively and significantly moderates the relationship between innovation strategies and organizational effectiveness.

H6a: Attraction positively and significantly moderates the relationship between innovation strategies and organizational effectiveness.

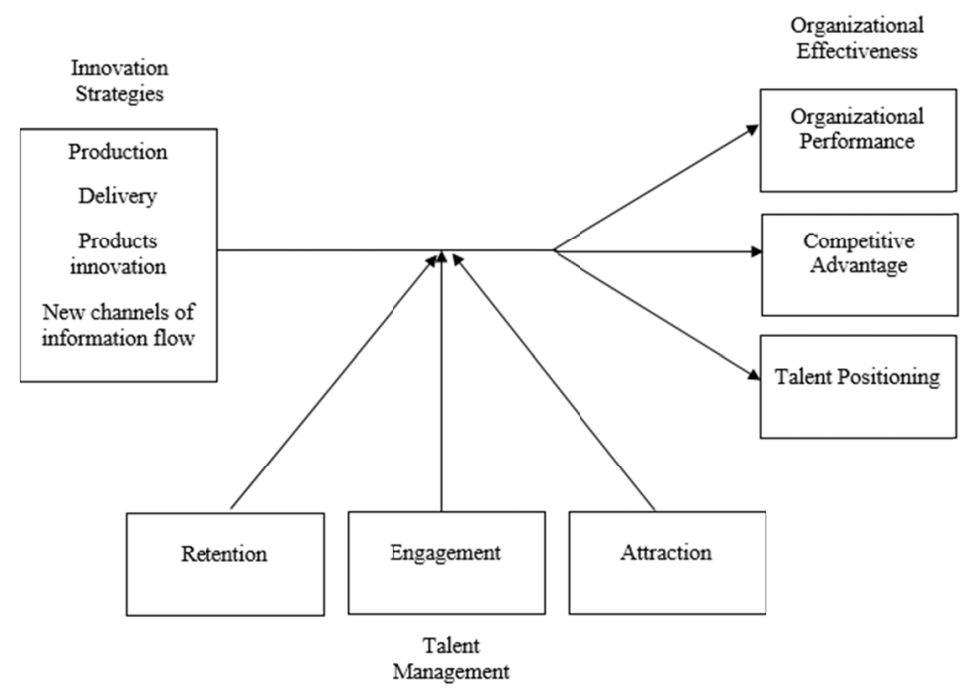

Figure 1. Conceptual framework

\section{Methodology}

\subsection{Study Design}

The study has adopted a quantitative design for evaluating the effect of a competitive innovative strategy on organizational effectiveness with the moderating role of talent management. The rationale behind the selection of the design is based on its effectiveness for gathering data objectively and representing it in the form of statistics. Additionally, this also removes the generalizability prospects in the research. 


\subsection{Study Population and Sample}

The population of the study constitutes of the employees working in the website development companies in Jordan. Among the 198 companies, the population derived contains 1009 employees. From the overall population, a sample of 279 participants was derived.

\subsection{Data Collection}

For the collection of data, the study conducted a survey using a close-ended questionnaire. It is selected because it allows the researcher to collect data in an effectual and cost-effective way. The questionnaire used comprised of four parts, where the first part collected demographic information of the employees while the other three parts revolved around innovation strategy, talent management, and organizational benefit. The innovation strategy comprised of two parts namely process innovation and product innovation, having 4 questions in each. While the talent management constitute of three parts such as retention, engagement, and attraction, which further comprised of 4 sub-items, respectively. Lastly, the organizational effectiveness includes three parts namely, its performance, competitive advantage and talent positioning, with 5 items in each. Therefore, a total of 35 sub-items have been presented in the close-ended questionnaire. Moreover, each item on the questionnaire was based on a 3-point Likert scale (i.e. as 1 to 3, from 1 agree to 3 disagree). The use of scale helps in assessing the participants' opinion on competitive innovative strategy on organizational effectiveness where talent management acts as a moderator.

\subsection{Data Analysis}

The collected data was assessed using the IBM Statistical Package for Social Sciences (SPSS) version 20.0. A structural equation modeling (SEM) has been applied via AMOS version 22.0 for analyzing the data collected. Moreover, confirmatory factor analysis (CFA) has been used to present the causal relationships between the variables. Descriptive statistics are presented for the demographic characteristics.

\section{Results}

The study assessed the questionnaire items for their reliability before distributing it among the study participants. For this, Cronbach Alpha is used, which assessed the reliability of each item inclusive in the questionnaire. The value of Cronbach Alpha has been illustrated in Table 1.

Table 1. Questionnaire reliability

\begin{tabular}{|c|c|c|}
\hline Variables & & Number of Items \\
\hline \multicolumn{3}{|c|}{ Innovation Strategy } \\
\hline \multicolumn{3}{|c|}{ Process Innovation } \\
\hline & PRI1 & 0.789 \\
\hline & PRI2 & \\
\hline & PRI3 & \\
\hline & PRI4 & \\
\hline \multicolumn{3}{|c|}{ Product Innovation } \\
\hline & PDI1 & 0.983 \\
\hline & PDI2 & \\
\hline & PDI3 & \\
\hline & PDI4 & \\
\hline \multicolumn{3}{|c|}{ Talent Management } \\
\hline \multicolumn{3}{|c|}{ Retention } \\
\hline & RET1 & 0.814 \\
\hline & RET2 & \\
\hline & RET3 & \\
\hline & RET4 & \\
\hline \multicolumn{3}{|c|}{ Engagement } \\
\hline & ENG1 & 0.832 \\
\hline & ENG2 & \\
\hline & ENG3 & \\
\hline & ENG4 & \\
\hline
\end{tabular}




\begin{tabular}{lll}
\hline Attraction & ATT1 & \\
& ATT2 & 0.778 \\
& ATT3 & \\
Organizational Effectiveness & ATT4 & \\
Organizational Performance & \\
& OP1 & \\
OP2 & 0.712 \\
OP3 & \\
OP4 & \\
OP5 & \\
Competitive Advantage & CA1 \\
CA2 & \\
CA3 & \\
CA4 & \\
CA5 & \\
& TP1 \\
TP2 & \\
TP3 & \\
TP4 & \\
TP5 & \\
\hline
\end{tabular}

Table 2 exhibits the demographic details of the participants. As per the responses of the participants, it is found that most of the participants were male $63.1 \%$ whereas the percentage of females was $36.9 \%$. In terms of age, the majority of the employees employed were aged below 30 years $41.6 \%$, followed by age group of 31 to 40 years $38.4 \%$, while participants aged above forty represent a percentage of $20.1 \%$. With regard to the qualification, the participants withholding bachelors were $79.8 \%$, while the percentage of masters was $14.4 \%$ with postgraduate and above was reported by $5.8 \%$. Along with it, the majority of the participants $36.6 \%$ have experienced less than 5 years, whereas $29.7 \%$ had experience between 5 to 10 years, while lowest percentage of employees above 15 years of experience was reported to be $11.8 \%$.

Table 2. Participants demographics $(\mathrm{n}=279)$

\begin{tabular}{llll}
\hline Variables & & N & \% \\
\hline Gender & Male & 176 & 63.1 \\
& Female & 103 & 36.9 \\
Age & & & \\
& Below 30 years & 116 & 41.6 \\
& 31-40 years & 107 & 38.4 \\
Qualification & 41 years or above & 56 & 20.1 \\
& & & \\
& Bachelors & 223 & 79.8 \\
Working Years & Masters & 40 & 14.4 \\
& Post Graduate and more & 16 & 5.8 \\
& Less than 5 years & 102 & 36.6 \\
& Between 5 to 10 years & 83 & 29.7 \\
& Between 11 to 15 years & 61 & 21.9 \\
& Above 15 years & 33 & 11.8 \\
& & 279 & 100.00 \\
\hline
\end{tabular}


Table 3 has presented the KMO and Bartlett's test to measure the sampling sufficiency and sphericity. According to Hair et al. (2016), KMO measure of sampling sufficiency have to be higher than 0.08 and Bartlett's test of Sphericity have to be statistically significant at $1 \%$ confidence interval. The requirements for both measures have been appropriately fulfilled in the below table.

Table 3. Bartlett's and KMO test

\begin{tabular}{lll}
\hline Kaiser-Meyer-Olkin Measure of Sampling Adequacy. & .831 \\
\hline Bartlett's Test of Sphericity & Approx. Chi-Square & 1056.832 \\
& Df & 104 \\
& Sig. & .000 \\
\hline
\end{tabular}

According to Hair et al. (2006, 2010), the fit indices for CMIN/DF, GFI, CFI, RMSEA, and PCLOSE should be greater than 0.85 threshold value. Below table has apparently shown that all the fit indices are achieved in the models. Therefore, confirmatory factor analysis and structural equation modeling was validated and significantly accurate due to the support of these model fitness (Table 4).

Table 4. Model fitness indices

\begin{tabular}{llll}
\hline & Threshold & CFA & SEM \\
\hline CMIN/DF & $<3.00$ & 1.433 & 1.532 \\
GFI & $>0.85$ & 0.917 & 0.882 \\
AGFI & $>0.80$ & 0.870 & 0.869 \\
CFI & $>0.90$ & 0.992 & 0.975 \\
RMSEA & $<0.08$ & 0.052 & 0.067 \\
PCLOSE & $>0.10$ & 0.751 & 0.282 \\
\hline
\end{tabular}

Table 5 below demonstrates the factor loadings validity means all the items of factors matching the significant level, which is 0.05 at $5 \%$ significance level. The below table displays that factor loading of construct items are matching the criteria of significant level. The threshold value of factor loading is 0.60 and; therefore, model factor loading value is larger than 0.60 .

Table 5. Construct validity

\begin{tabular}{lllll}
\hline & & & Estimate & P Value \\
\hline PI5 & $<---$ & PI & 0.773 & 0.000 \\
PI1 & $<---$ & PI & 0.861 & 0.000 \\
PI4 & $<---$ & PI & 0.602 & 0.000 \\
PI2 & $<---$ & PI & 0.682 & 0.000 \\
PI3 & $<---$ & PI & 0.714 & 0.000 \\
RET1 & $<---$ & RET & 0.642 & 0.000 \\
RET2 & $<---$ & RET & 0.877 & 0.000 \\
RET3 & $<---$ & RET & 0.629 & 0.000 \\
RET4 & $<---$ & RET & 0.652 & 0.000 \\
ENG3 & $<---$ & ENG & 0.761 & 0.000 \\
ENG1 & $<---$ & ENG & 0.871 & 0.000 \\
ENG2 & $<---$ & ENG & 0.798 & 0.000 \\
ENG4 & $<---$ & ENG & 0.642 & 0.000 \\
ATT1 & $<---$ & ATT & 0.765 & 0.000 \\
ATT3 & $<---$ & ATT & 0.844 & 0.000 \\
ATT4 & & ATT & 0.661 & 0.000 \\
ATT5 & & ATT & 0.681 & 0.000 \\
OP3 & & OP & 0.714 & 0.000 \\
OP1 & & OP & 0.742 & 0.000 \\
OP2 & & OP & 0.698 & 0.000 \\
OP4 & & OP & 0.635 & 0.000 \\
CA3 & & CA & 0.663 & 0.000 \\
CA2 & & CA & 0.782 & 0.000 \\
CA3 & & CA & 0.684 & 0.000 \\
CA4 & & CA & 0.672 & 0.000 \\
TP3 & & TP & 0.789 & 0.000 \\
TP2 & & TP & 0.616 & 0.000 \\
TP3 & & TP & 0.687 & 0.000 \\
TP4 & & TP & 0.619 & 0.000 \\
\hline & & & & \\
\hline
\end{tabular}


Table 6 showed convergent validity outcomes revealed that the Average Variance Extracted (AVE) threshold value is 0.50 and for composite reliability threshold value is 0.70 .

Table 6. Convergent validity

\begin{tabular}{lll}
\hline & CR & AVE \\
\hline PI & 0.816 & 0.563 \\
RET & 0.982 & 0.842 \\
ENG & 0.725 & 0.716 \\
ATT & 0.783 & 0.655 \\
OP & 0.867 & 0.782 \\
CA & 0.781 & 0.718 \\
TP & 0.857 & 0.918 \\
\hline
\end{tabular}

The below table 7, indicates that all the construct variables justify standard as the AVE square root for every particular variable construct have greater values than the pertinent other constructs. Consequently, criteria for discriminant validity of all the constructs have been confirmed.

Table 7. Discriminant validity

\begin{tabular}{llllllll}
\hline & PI & RET & ENG & ATT & OP & CA & TP \\
\hline PI & $\mathbf{0 . 8 7 6}$ & & & & & & \\
RET & 0.036 & $\mathbf{0 . 8 5 3}$ & & & & & \\
ENG & 0.246 & 0.423 & $\mathbf{0 . 7 7 9}$ & & & & \\
ATT & 0.09 & 0.562 & 0.548 & $\mathbf{0 . 7 6 2}$ & & & \\
OP & 0.067 & 0.070 & 0.073 & 0.081 & $\mathbf{0 . 8 9 3}$ & & \\
CA & 0.043 & 0.019 & 0.019 & 0.033 & 0.003 & $\mathbf{0 . 8 5 6}$ & \\
TP & 0.066 & 0.041 & 0.053 & 0.010 & 0.089 & 0.091 & $\mathbf{0 . 8 4 1}$ \\
\hline
\end{tabular}

Table 8 has exhibited the regression coefficients. The findings have revealed a significant and positive effect of process innovation on organizational effectiveness $(\mathrm{P}=0.005)$. Similarly, the study has shown a positive and significant effect of attraction $(\mathrm{P}=0.006)$ and retention $(\mathrm{P}=0.003)$ on organizational effectiveness. However, the study failed to find any significant effect of engagement on the organizational effectiveness $(\mathrm{P}=0.712)$. Innovation strategies have shown a positive and significant mediating effect on retention $(\mathrm{P}=0.042)$, engagement $(\mathrm{P}=0.028)$, and attraction $(\mathrm{P}=0.038)$.

Table 8. Path analysis

\begin{tabular}{|c|c|c|c|c|c|c|}
\hline & & & Estim & S. & $\mathrm{T}-\mathrm{St}$ & $\mathrm{P}$ \\
\hline & & & ate & E. & ats & Value \\
\hline PI & $--->$ & $\mathrm{OE}$ & 0.416 & 0.087 & 4.007 & 0.005 \\
\hline RET & $--->$ & $\mathrm{OE}$ & 0.365 & 0.128 & 3.996 & 0.003 \\
\hline ENG & $--->$ & $\mathrm{OE}$ & 0.048 & 0.134 & 0.372 & 0.712 \\
\hline ATT & $--->$ & $\mathrm{OE}$ & 0.048 & 0.442 & 2.721 & 0.006 \\
\hline PI & $--->$ & RET & 0.077 & 0.096 & 0.757 & 0.042 \\
\hline PI & $--->$ & ENG & 0.062 & 0.013 & 0.619 & 0.028 \\
\hline PI & $--->$ & ATT & 0.033 & 0.044 & 0.233 & 0.038 \\
\hline
\end{tabular}

\section{Discussion}

The findings of the study reveal that the integration of talent management and innovation strategies are essential for the attainment of the competitive advantage. As per the responses of the participants, it is found that talent management serves as the catalyst towards the development of the organizational effectiveness and its sustainment of the competitive position in the business environment. The study reports that instilling effective talent management practices makes the employee use his skills for developing the competency of the 
organizations in Jordan. Bayyurt and Rizvi (2015) which assessed the talent management effect on the competitiveness of the Pakistani organization have reported similar results. A study on Kenya by Lyria (2015) also highlights the improvement of the process in Securities Exchange organization because of improved management of talent. A recent study of Najm and Manasrah (2017) on Jordan Bank also supplements the study finding pointing towards the effect of talent management for the achievement of a competitive edge.

The results of the study also highlight that the organization must view competitive advantage as a key component in innovation strategies based on its capability to assimilate the different components together. These are in line with the study of Anwar (2014) which elucidates that the talented people in the organization serve as a non-material competitive advantage as other in the market cannot imitate it. Krishnan and Scullion (2017) adds that a talented workforce integrates into the knowledge for improving the activities of the organization for sustainment of unique competitive advantage. Mohammed (2016) has illustrated a positive effect of employee talent management in terms of engagement, and retention as well as value addition advancing organization performance. The assessed variables also highlight that talent management helps the organization in its retention, engagement, and attraction of the best talent. These findings are consistent with the study of Kehinde (2012) which showed that investment of the organization in its retention of best talent allows it to continue its competitive advantage over others.

Supplementing the study results for the achievements of organization effectiveness by the amalgamation of the competitive advantage, Shrimali and Gidwani (2012) reports that growing competition for the skilled talents influences the organization achievement of its goals, while Urbancova (2013) reports increase engagement promotes innovation accelerating success and competition in the present competitive business environment. Fakhr El-Din (2013) also supports the findings by stating that the attraction capacity of the organization enhances given the high performance where talent management acts as a stimulus.

The study findings pertaining to the organization effectiveness has further been endorsed by Bethke-Langenegger et al. (2011), which found talent management as the most significant component in the attainment of competitive edge, based on its use as a part of retention and planning strategy. These results are also endorsed by Ramadan (2012) who stated that organizational effectiveness enhances due to talent management practices based on its strong relationship with a competitive advantage in terms of its increase and maximization. The results of the present study are parallel with Khurshid and Darzi (2016) which supplements that the talent management as a part of its competitive innovative strategy allows the organizations in sustainment of their significant market share as well as competitive position in the globalized business arcade.

\section{Conclusion}

The findings of the study conclude talent management as a moderator is essential for organizations to adopt allowing them to enhance their performance and sustain their competitive edge in the market. Along with it, it highlights that the integration of innovation practices allows the organizations to form an effective workforce, which contributes to their performance enhancement. Since the web development companies in Jordan lack the innovative regulation practices, therefore, the integration of talented workforce can help them in reshaping their strategies and work practices for performance growth. Consequently, it suggests that organization must improvise its practice for managing its talent which not only ensures its success at an internal level but also expands its reach for the attainment of global competitiveness.

At this juncture, the study concludes that adaptation of the innovative strategies allows the organization to effectively utilize its resources and assimilate the efforts of the organization different components towards a common innovation goal serving as a competitive gain. While carrying out the study, certain limitations were observed in terms of its generalizability. Such as application of study results remain limited to the region of Jordan and to web development companies only. Further, it also directs future studies to assess the effect of information flow within the organization. Also, the managers' perspective can also be evaluated in terms of their role in talent management.

\section{Acknowledgement}

The author is appreciative to every related personnel in any reference that added for the purpose of the current research. Additionally, this research has no conflict of interest and not financed by any source.

\section{References}

Adnan, Z., Abdullah, H. S., \& Ahmad, J. (2016). Assessing the Moderating Effect of Competition Intensity on HRM Practices and Organizational Performance Link: The Experience of Malaysian R\&D Companies. Procedia Economics and Finance, 35, 462-467. 
Al-Qeed, M. A., Al-raggad, M. A., Al-shura, M. S., Alqaisieh, N. M., \& Al-Azzam, Z. F. (2016). The Impact of Ideal Employee Award on the Retention of Distinctive Competencies in Public Sector Organizations in the Hashemite Kingdom of Jordan: A Field Study of Public Sector Employees Who Obtained the Ideal Employee Award Civil Service Bureau. International Journal of Business and Social Science, 7(3), 104-114.

Anwar, A., Nisar, Q. A., Khan, N. Z. A., \& Sana, A. (2014). Talent management: Strategic priority of organizations. International Journal of Innovation and Applied Studies, 9(3), 63-75.

Asomaning, R., \& Abdulai, A. (2015). Empirical evidence of the market orientation-market performance relationship in Ghanaian small businesses. Educational Research International, 4(2), 69-86.

Autant-Bernard, C., Fadairo, M. \& Massard, N. (2013). Knowledge diffusion and innovation policies within the European regions: Challenges based on recent empirical evidence. Research Policy, 42 (1), 196-210. http://dx.doi.org/10.1016/j.respol.2012.07.009

Bayyurt, N., \& Rizvi, S. (2015). Impact of talent management on perceived organizational effectiveness: service industry in Lahore, Pakistan. Research Journal of Business and Management, 2(4), 468-487. https://doi.org/10.17261/pressacademia.2015414450

Bethke-Langenegger, P., Mahler, P., \& Staffelbach, B. (2011). The effectiveness of talent management strategies. European Journal of International Management, 5(5), 524-539. https://doi.org/10.1504/ejim.2011.042177

Beyene, K. T., Shi, C. S., \& Wu, W. W. (2016). The impact of innovation strategy on organizational learning and innovation performance: Do firm size and ownership type make a difference? South African Journal of Industrial Engineering, 27(1), 125-136. http://dx.doi.org /10.7166/27-1-1308

Björkman, I., Ehrnrooth, M., Mäkelä, K., Smale, A., \& Sumelius, J. (2013). Talent or not? Employee reactions to talent identification. Human Resource Management, 52(2), 195-214. https://doi.org/10.1002/hrm.21525

Camisón, C., \& Villar-López, A. (2014). Organizational innovation as an enabler of technological innovation capabilities and firm performance. Journal of business research, 67(1), 2891-2902. https://doi.org/10.1016/j.jbusres.2012.06.004

Diab, A. (2014). Joel Trammell cautions CEOs to manage employee stress by understanding motivation. Tech Cocktail. Retrieved from http://tech.co/joeltrammell-employee-stress-2014-11.

Distanont, A., \& Khongmalai, O. (2018). The role of innovation in creating a competitive advantage. Kasetsart Journal of Social Sciences. https://doi.org/10.1016/j.kjss.2018.07.009

Fakhr El-Din, H. (2013). The effect of talent management on organizational success: A comparative study in the petroleum sector in Egypt. Journal of US-China Public Administration, 10(4), 358-367.

Fapohunda, T. (2014). Increasing organizational effectiveness through better talent management. Research Journal of Human Resource, 2(4), 1-14.

García-Sánchez, E., García-Morales, V. J., \& Martín-Rojas, R. (2018). Influence of Technological Assets on Organizational Performance through Absorptive Capacity, Organizational Innovation and Internal Labour Flexibility. Sustainability, 10(3), 1-25. https://doi.org/10.3390/su10030770

Gelens, J., Dries, N., Hofmans, J., \& Pepermans, R. (2013). The role of perceived organizational justice in shaping the outcomes of talent management: A research agenda. Human Resource Management Review, 23(4), 341-353. https://doi.org/10.1016/j.hrmr.2013.05.005

Gelens, J., Hofmans, J., Dries, N., \& Pepermans, R. (2014). Talent management and organisational justice: Employee reactions to high potential identification. Human Resource Management Journal, 24(2), 159-175. https://doi.org/10.1111/1748-8583.12029

Hair Jr, J. F., Hult, G. T. M., Ringle, C., \& Sarstedt, M. (2016). A primer on partial least squares structural equation modeling (PLS-SEM). Sage Publications.

Hair, J. F., Black, WC, Babin, BJ, \& Anderson, RE (2010). Multivariate data analysis, 7.

Hajir, J., Obeidat, B., Al-dalahmeh, M., \& Masa'deh, R. (2015). The role of knowledge management infrastructure in enhancing innovation at mobile telecommunication companies in Jordan. European Journal of Social Sciences, 50(3), 313-330.

Hotho, J. J., Lyles, M. A., \& Easterby-Smith, M. (2015). The mutual impact of global strategy and organizational learning: Current themes and future directions. Global Strategy Journal, 5(2), 85-112. 
https://doi.org/10.1002/gsj.1097

Kehinde, J. (2012). Talent management: Effect on organization performances. Journal of Management Research, 4(2), 178-186. https://doi.org/10.5296/jmr.v4i2.937

Khurshid, R., \& Darzi, M. A. (2016). Managing talent for competitive advantage. International Journal of Applied Research, 2(2), 569-571.

Kibisu, M. C., \& Awino, Z. B. (2017). The Moderating Effect of Innovation on the Relationship between Enterprise Risk Management Strategies and Performance of Christian Hospitality Sector in Kenya-An Empirical Overview. International Journal of Business and Management, 12(12), 212-223. https://doi.org/10.5539/ijbm.v12n12p212

Krishnan, T. N., \& Scullion, H. (2017). Talent management and dynamic view of talent in small and medium enterprises. Human Resource Management Review, 27(3), 431-441. https://doi.org/10.1016/j.hrmr.2016.10.003

Lu, Y., Zhou, L., Bruton, G., \& Li, W. (2010). Capabilities as a mediator linking resources and the international performance of entrepreneurial firms in an emerging economy. Journal of International Business Studies, 4l(3), 419-436. https://doi.org/10.1057/jibs.2009.73

Lyria, R. K. (2013). Role of Talent Management on Organizational Performance in Companies Listed in Nairobi Security Exchange.

Lyria, R. K. (2015). Effect of Talent Management on Organizational Performance in Companies Listed in Nairobi Securities Exchange in Kenya (Doctoral dissertation).

Martín-de Castro, G., Delgado-Verde, M. Navas-López, J. E. \& Cruz-González, J. (2013). The moderating role of an innovation culture in the relationship between knowledge assets and product innovation. Technological Forecasting and Social Change, 80(2), 351-363. http:// dx.doi.org/10.1016/j.techfore.2012.08.012

Mohammed, A. (2016). The Impact of Talent Management on Employee Engagement, Retention and Value Addition in Achieving Organizational Performance. International Journal of Engineering and Management, 1(12), 142-152.

Mohammed, A. B. (2011). Jordan Software Industry: Investigating the Role of Human Capital. International Journal of Business and Management, 6(5), 217-227. https:// doi:10.5539/ijbm.v6n5p217

Najm, A., \& Manasrah, A. K. (2017). The effect of talent management on organizational performance: applied study in Jordanian banks. Review of Applied Socio-Economic Research, 13(1), 36-51.

Nijveld, J. (2014). Role of global talent management in organizational performance (Bachelor's thesis, University of Twente).

Noruzy, A., Dalfard, V. M., Azhdari, B., Nazari-Shirkouhi, S. \& Rezazadeh, A. (2013). Relations between transformational leadership, organizational leasing, knowledge management, organizational innovation and organizational performance: an empirical investigation of manufacturing firms. The International Journal of Advanced Manufacturing Technology, 64(5-8), 1073-1085. http://dx.doi.org/10.1007/s00170-012-4038-y

Payambarpour, S. A., \& Hooi, L. W. (2015). The impact of talent management and employee engagement on organisational performance. International Journal of Management Practice, 8(4), 311-336.

Perry-Smith, J. E., \& Mannucci, P. V. (2017). From creativity to innovation: The social network drivers of the four phases of the ideal journey. Academy of Management Review, 42(1), 53-79. https://doi.org/10.5465/amr.2014.0462

Ramadan, W. H. (2012). The Influence of Talent Management on Sustainable Competitive Advantage of Small and Medium-Sized Establishments. E-Leader Berlin, 1-15.

Rastgoo, P. (2016). The relationship of talent management and organizational development with job motivation of employees. Acta Universitatis Agriculturae et Silviculturae Mendelianae Brunensis, 64(2), 653-662. https://dx.doi.org/10.11118/actaun201664020653

Shrimali, H., \& Gidwani, B. (2012). Role of talent management in sustainable competitive advantage: Rising to meet the business challenges. Pacific business review international, 4(3), 29-33.

Sintset Kenfac, G., Nekoumanesh, S., \& Yang, M. (2013). Process Innovation: Impacts on Organization's Performance: A Qualitative Study of Four Swedish Municipalities. 
Tseng, M. L., Tan, R. R., \& Siriban-Manalang, A. B. (2013). Sustainable consumption and production for Asia: sustainability through green design and practice. Journal of Cleaner Production, 40, 1-5. https://doi.org/10.1016/j.jclepro.2012.07.015

Tuan, N., Nhan, N., Giang, P., \& Ngoc, N. (2016). The effects of innovation on firm performance of supporting industries in Hanoi, Vietnam. Journal of Industrial Engineering and Management, 9(2), 413-431. https://doi.org/10.3926/jiem.1564

Urbancova, H. (2013). Competitive advantage achievement through innovation and knowledge. Journal of Competitiveness, 5(1), 82-96. https://doi.org/10.7441/joc.2013.01.06

Vaiman, V., Scullion, H., \& Collings, D. (2012). Talent management decision making. Management Decision, 50(5), 925-941. https://doi.org/10.1108/00251741211227663

Vaughan, E.J. \& Vaughan T.M, (2014). Fundamentals of risk and insurance (5th ed.). John Wiley and Sons. New York. https://doi.org/10.2307/252935

Virameteekul, V. (2011). Message from the ministry of science and technology. Retrieved from www.thailandinnovativecompanies.com/ttd_bizenterprise/Indprof/TTIC/TTIC_2011_IPO2.pdf

Zemplinerová, A. (2010). Inovační aktivita firem a konkurence. Politická ekonomie, 58(6), 747-760. https://doi.org/10.18267/j.polek.760

\section{Copyrights}

Copyright for this article is retained by the author(s), with first publication rights granted to the journal.

This is an open-access article distributed under the terms and conditions of the Creative Commons Attribution license (http://creativecommons.org/licenses/by/4.0/). 